\title{
Welcoming with Risk Classification in the Hospital São Paulo's Emergency Department
}

\author{
Acolbimento com Classificação de Risco no Pronto-Socorro do Hospital São Paulo \\ Acogida con Clasificación de Riesgo en el servicio de emergência del Hospital Sao Paulo
}

\author{
Flávia Saraiva Leão Fernandes ${ }^{1}$, Beatriz de Souza Lima ${ }^{2}$, Maria Nazaré Ribeiro $^{3}$
}

\begin{abstract}
Objective: Describe the implementation of the Welcoming with Risk Classification in the Hospital São Paulo's Emergency Department, as well as present its theoretical reference. The Protocol determines the waiting time for health treatment based on the severity of the patient's condition, and it is performed by a registered nurse. The Welcoming with Risk Classification strategy enables the organization of patient flow and better identification of patients, giving priority to patients with greater risks of death and health problems; offers information to citizens who seek Hospital São Paulo about the Brazilian public health system (SUS); shows the kind of healthcare and the type of patient that are present in the hospital (most of the patients could have sought other levels of care such as primary care). The implementation process generated subsidies for the discussion on the role of the HSP ED within SUS in the city of São Paulo.
\end{abstract}

Keywords: Emergency medical services; Public health; Hospitals, teaching; Humanization of assistance

\section{RESUMO}

Objetivo: Descrever o processo de implantação do Acolhimento com Classificação de Risco no Serviço de Urgência do Hospital São Paulo, bem como apresentar seu referencial teórico. O protocolo teve por objetivo determinar o tempo de espera pela atenção baseado na gravidade do paciente, e foi operacionalizado por uma enfermeira. A estratégia do Acolhimento com Classificação de Risco possibilita a organização do fluxo e a melhor identificação de pacientes, dando prioridade àqueles com risco de morte ou agravos à saúde; provê um momento de orientação aos cidadãos que procuram o HSP em relação ao SUS; torna evidente o tipo de assistência à saúde e de paciente presente no hospital (a maioria apresenta queixas de baixa e média complexidade, passíveis de resolução em unidades de menor complexidade). O processo de implementação desta estratégia trouxe subsídios para a discussão sobre o papel do Pronto-Socorro do HSP, dentro do SUS em São Paulo.

Descritores: Serviços médicos de emergência; Saúde pública; Hospitais de ensino; Humanização da assistência

\section{RESUMEN}

Objetivo: Describir el proceso de implantación de la Acogida con Clasificación de Riesgo en el Servicio de Emergencia del Hospital Sao Paulo, así como presentar su referencial teórico. El protocolo tuvo por objetivo determinar el tiempo de espera para la atención basada en la gravedad del paciente, y fue operacionalizado por una enfermera. La estrategia de la Acogida con Clasificación de Riesgo posibilita la organización del flujo y la mejor identificación de los pacientes, dando prioridad a aquellos con riesgo de muerte o gravedad de la salud; provee un momento de orientación a los ciudadanos que buscan el HSP en relación al SUS; se torna evidente el tipo de asistencia a la salud y de paciente presente en el hospital (la mayoría presenta quejas de baja y mediana complejidad, pasibles de resolución en unidades de menor complejidad). El proceso de implementación de esta estrategia trajo subsidios para la discusión sobre el papel del servicio de emergencia del HSP, dentro del SUS en Sao Paulo. Descriptores: Servicios médicos de urgencia; Salud Pública; Hospitales escuela; Humanización de la atención

\footnotetext{
${ }^{1}$ Masters in Collective Health of Hospital São Paulo Emergency Department, Universidade Federal de São Paulo - UNIFESP - São Paulo (SP), Brazil.

${ }^{2}$ Masters in Collective Health. Hospital São Paulo Nephrology/Hemodialysis Department. Universidade Federal de São Paulo - UNIFESP - São Paulo (SP), Brazil. ${ }^{3}$ Specialized in Cardiologic Nursing. Nursing manager of Hospital São Paulo Emergency Department. Universidade Federal de São Paulo - UNIFESP - São Paulo (SP), Brazil.
} 


\section{INTRODUCTION}

The Brazilian Unified Health System (Sistema Único de Saúde - SUS) is organized in a pyramidal form with the purpose of respecting the doctrinal principles of the Brazilian public health system (universal access, equity, and integrality in healthcare) and to enable the proposal for the "regionalization and hierarchical organization of health services." This healthcare model has in its base Primary Healthcare, which is a set of health actions that can be individual or collective, towards health promotion and protection, injury and disease prevention, diagnose, treatment, rehabilitation and health mantainance. It is developed in a teamwork form, directed toward a population residing in very delimited territories, for which the health team takes responsibility. It uses low density technologies that should solve the most frequent and relevant health problems in its territory. It is done by Basic Healthcare Centers (in most cases through the Family Health Strategy) and sets a "gateway" to other more complex levels of healthcare ${ }^{(1)}$.

The mid-level complexity care is the pyramid's middle part, consisting of specialized clinical and surgical outpatient medical care, diagnostic and therapeutical support services, and medium size hospitals. They take care of referred patients from Primary Health Care and have to either counter-reference to Basic Healthcare Centers or refer for high-complexity care. At the pyramid's top are the larger hospitals responsible for the high-complexity care. They offer high cost procedures that use high-density technology and are reference for other programs and services of the healthcare system ${ }^{(2)}$.

This healthcare model's main goals, besides rationalization of resources, are to direct patient flow into the healthcare system and address their health necessities in the adequate place. Primary Health Care is responsible for the initial diagnosis, with interventions inside de primary care scope, and referrals for superior complexity levels, stablishing a gateway to the rest of the system ${ }^{(3)}$.

However, the increase in life expectancy and decrease of child mortality detected in the last years, cause demographic and epidemiological transitions that affect the healthsystem care. In the last 60 years, the Brazilian population has increased by threefold and life expectancy by 20 years, a fact that resulted in a greater number of elders in the general population. Due to cientific and technological advances, it is possible to perceive a decrease in mortality by contagious infectious diseases and an increase in the incidence of chronic degenerative diseases in Brazil. This group of factors contributes to the increase of healthcare demand.

In reality, the abovementioned factors cause the actual everyday experience of the SUS patient and healthcare professional to be far from ideal. This perception comes from our daily work in the Hospital São Paulo's Emergency Room.

Therefore, the nurses in Hospital São Paulo (HSP) Emergency Department (ED) detect every day cases of inappropriate use of emergency services. For example, patients with low complexity complaints which could be addressed in Primary Care or smaller hospitals; chronic patients who worsen for lack of monitoring; private insurance patients who, because of lack of health plan coverage, seek public ED for high cost procedures and exams; referrals from non-integrated health services (non regionalized from other cities and even other states); lack of equity in the care; and so forth. This scenario can be found in several other emergency medical services throughout the country due to a doctor-centered model of health care that operates in a complaint-conduct basis, which causes overcrowding in the hospitals ${ }^{(4)}$.

Because the Hospital São Paulo's ED operates in an "open door" policy, in other words, caring for patients who seek care spontaneously, it receives an extremely diverse patient population that is superior to its capacity and supply of beds. In addition, setting priorities in the emergency care becomes harder to do when treating patients according to their order of arrival.

In this scenario, a need was detected to organize patient flow through the ED in order to welcome the patients and guarantee better access to emergency care.

This study had the objective to describe the strategy of the Welcoming with Risk Classification in the Hospital São Paulo's Emergency Department, as well as present its theoretical reference. Moreover, this article presents the developments provided by the process of implementation.

\section{HumanizaSUS AND WELCOMING WITH RISK CLASSIFICATION}

Since 2000, various initiatives in the healthcare humanization field were developed showing the need for answers to the health crisis identified as the SUS collapse ${ }^{(5)}$. These were isolated projects considered to be important collaborations and which accumulated significant experiences. In 2003, a need was defined for a policy that would include the existing projects, overcoming each particularity, in order to empower the concept of humanization for the series of SUS' health practices ${ }^{(6)}$. Therefore, the National Policy for the Humanization of SUS' Healthcare and Management (HumanizaSUS) was instituted in 2003 by the Health Ministry in response to the growing demand for quality improvement in healthcare for users and in working conditions for the health professionals.

In order to achieve its objectives, the HumanizaSUS offers managers technologies and ways to implement the humanization. The various devices include the Welcoming with Risk Classification in health equipment, 
among others. In 2009, the Health Ministery published a handbook entitled "Welcoming with Risk Classification in Emergency Services". It is part of a collection entitled "HumanizaSUS Handbooks" with the purpose of disseminating healthcare and health management humanization technologies.

The strategy of welcoming agrees with the SUS' principles, since it aims to reorganize health services to ensure universal access and integrated care. In other words, it aims to care for everyone who seeks the service, assuming a welcoming role that practices listening and gives positive answers to users' needs ${ }^{(7)}$. It is considered a strategy that favors a trustworthy relationship and commitment between health teams and health services and it is considered the most political, ethical and esthetical relevant guideline of the HumanizaSUS ${ }^{(8)}$.

On the other hand, the risk classification organizes the queue service based on different criteria other than the order of arrival. It looks to ensure immediate care to high risk patients; inform patients and families the likely waiting time; promote teamwork by continuous analysis of the process; increase user satisfaction; and, mainly, enable and instigate processes of building internal and external pacts and networks of healthcare ${ }^{(9)}$.

It does not aim to offer pre-diagnosis nor exclude people before receiving medical care. Therefore, it must be held by a registered nurse following a protocol agreed on by the medical staff. This protocol must be formed by consensus to evaluate the gravity and potential of patients' worsening, as well as the patients' level of suffering. It is important to note that the protocol must guide the risk classification but not determine it, since it does not include subjective factors of evaluation such as emotional, cultural and social aspects of each case ${ }^{(8)}$.

\section{THE HOSPITAL SÃO PAULO}

The Hospital São Paulo, maintained by the Associação Paulista para o Desenvolvimento da Medicina (SPDM), is a general hospital considered to be of tertiary reference, since it takes care of patients with high complexity diseases. It is also considered a teaching hospital, because it serves as the practical and scientific field to the Universidade Federal de São Paulo. Its mission is to provide healthcare to the Brazilian population by the Sistema Único de Saúde. It has 743 beds: 651 for adults and 92 pediatric.

The HSP Emergency Department provides healthcare to adults and children and consists of different medical specializations. The clinical staff consists of one general medical coordinator, one doctor in charge of the "Plantão Controlador Universitário" and teams of chief doctors, contracted physicians and medical residents. The nursing team is formed by a nurse manager, nurse in charge, nurses, resident nurses and nursing staff (nurs- ing technicians and assistants). Besides, there is a social worker and administrative staff.

For the operation of the Welcoming with Risk Classification in São Paulo Hospital, an institutional protocol was developed. Following a literary review and the situational diagnosis of the HSP' Emergency Department the protocol based on signs and symptoms was created. It determines the waiting time for health treatment based on the severity of the patient's clinical conditions.

It was determined that the responsibility for the protocol should be held by registered nurses. With the assistance of nursing technicians and assistants, nurses perform the nursing consultation and, based on the patient's clinical status, complaints and duration, as well as personal history, the nurses assign a color to the patient that corresponds to the appropriate waiting time. There are four colors in the protocol. The color red corresponds to the need for immediate care ( 0 minutes of waiting time); orange corresponds to the need for emergency care, as soon as possible (15 minutes at the most); yellow corresponds to the need for emergency care (60 minutes at the most); green means a priority care, but not urgent, with waiting time up to 120 minutes; and blue guides the nun-urgent care that respects the order of arrival.

After the patient arrives at HSP ED, they are welcomed by a nurse or a social worker who discovers the reasons for seeking the ED. They inform the patients and their family about the healthcare model of Welcoming and Risk Classification; the waiting time for medical care, and the possibility, depending on the case, of healthcare in other health services integrated in SUS, such as Outpatient Medical Care Units (AMA) and Basic Health Units (UBS). The patient is instructed to go to the information desk and register for healthcare where a registration form is printed for the Risk Classification sector. Two nurses, with the assistance of two auxiliary nurses, perform nursing consultation and classify the patitent by color and the adequate medical specialization. The classification is based on the reasons for seeking healtcare and the signs and symptoms, guided by the institutional protocol. The patients rated with the color red are referred to the Emergency Rooms in order to receive immediate care. The other patients go to the different specialization sectors.

It is important to notice that patients that come to HSP ED by ambulance and by the police, or even patients who are evidently in a state of emergency go straight to the Emergencies Rooms and are not rated by the nurse.

Although there are implications in the process of implementation of the Welcoming with Risk Classification in emergency medical services such as high patient turnover; high number of patients; troubled environment; lack of privacy and conditions of structure ${ }^{(10)}$, its implementation in Hospital São Paulo's Emergency Department 
was favorable to the process of healthcare. It enabled the organization of patient flow and better identification of patients, giving priority to patients with greater risks of death and health problems. Directing patients to the adequate specialization quickly is directly related to better prognosis of the disease and to protect patients from side effects and consequences related to their main complaint. Therefore, it is possible to affirm that this strategy is favorable to improving the quality of healthcare in Hospital São Paulo's Emergency Department.

The Welcoming with Risk Classification offers information to citizens who seek Hospital São Paulo about the SUS. During the consultations, the nurse and/or social worker can explain when emergency services should be sought, the importance of bonding with the Basic Health Unit of reference, and other specialized health services that receive spontaneous demand. This strategy helped to decrease de volume of patients who seek the HSP ED inappropriately looking for diagnostic exams and non-urgent specialized consultations.

Furthermore, this strategy showed the kind of healthcare and the type of patient that are present in the HSP ED. According to data collected in reports developed by the Information Systems Division of the HSP, a total of 121,554 patients were rated by the nurses of the Welcoming with Risk Classification during the period of January 1st 2011 and November 30th 2011. A total of 4,662 (3.8\%) patients were assigned the "Red" priority (need for immediate care); 5,872 (4.8\%) "Orange"; 18,320 (15.2\%) "Yellow" (urgent care); 64,861 (53.3\%) "Green" (standard care); and 27,839 (22.9\%) "Blue" (non-urgent care). It should be noted that with this data most of the patients $(92,700-76.3 \%)$ did not need immediate/ urgent care. The urgent population represented only $26 \%$ $(28,854-23.7 \%)$ of the total.

These facts lead us to a discussion of the role of emergency facilities inside a health system that provides universal coverage with integrated care. Most of the patients could have sought other levels of care such as primary care. This type of use increases the demand and competes with true emergency cases. A number of different studies about ED demand profile corroborate these findings ${ }^{(11-15)}$.

Ninety percent of the cases in the Hospital das Clínicas de São Paulo's Emergency Department was released after consultation, which led the conclusion that this ED is a primary and mid-level healthcare provider and indicated an inversion in patient flow relative to the healthcare hierarchy ${ }^{(11)}$.

Some studies use the concept of adequacy of cases to the role of emergency services. Generally, the inad- equate cases are defined as non-urgent cases or cases that could have been resolved in primary healthcare. The percentage of cases considered inadequate in Brazilian studies, are higher than $50 \%$. A study performed in $\mathrm{Ala}$ goas demonstrated that the percentage of inadequate cases was $84 \%{ }^{(12)}$; in Santa Maria, Rio Grande do Sul, it was $60.6 \%{ }^{(13)}$; in Santa Catarina, in the ED of the University Hospital, it was $65 \%{ }^{(14)}$; and in Pernambu$\mathrm{co}$, in the Hospital da Restauração, the percentage of inadequate cases was $74.5 \%{ }^{(15)}$. The high demand for emergency medical services is due to the enormous legitimacy that these services have to the population, since they have high technology available and usually great geographical accessibility in the city; and the population have confidence in the professionals and high expectations/satisfaction with the quality of care ${ }^{(16)}$. Other studies and research on the HSP ED's demand profile are required because there are none published on this subject matter.

\section{FINAL CONSIDERATIONS}

The implementation of the Welcoming with Risk Classification strategy in Hospital São Paulo's Emergency Department caused great impact in the service routine both at the management level as well as the level of care. The ED's management team now has data to subsidize interventions and the multiprofessional team, responsible for the care, has mechanisms to set emergency treatment priorities.

Challenges still lie ahead, however. The high number of patients strains the capacity of care to the bursting point. The nursing team was increased in size at the time of the strategy implementation; however, new situational diagnoses are necessary to subsize the new post-implementation reality.

The implementation process generated subsidies for the discussion on the role of the HSP ED within SUS in the city of São Paulo. The number of low complexity cases in the ED increases this demand and competes for resources with true emergency cases. Therefore, an evaluation of primary and secondary care is necessary as well as the integration of emergency services with other health services in order to better serve the population. Other studies are being done at the Universidade Federal de São Paulo on the role of emergency services in the healthcare system.

This study has some limitations, such as the impossibility to evaluate the strategy as a humanization tool, as well as to generalize its developments to characterize the Hospital São Paulo's Emergency Department's demand. 


\section{REFERENCES}

1. Brasil. Ministério da Saúde. Secretaria de Atenção à Saúde. Departamento de Atenção Básica. Política nacional de atenção básica Brasília: Ministério da Saúde; 2006.

2. Brasil. Ministério da Saúde. Conselho Nacional das Secretarias Municipais de Saúde. O SUS de A a Z. Garantindo saúde nos municípios. $3^{\text {a }}$ ed. Brasília: Ministério da Saúde; 2009. (Série F. Comunicação e Educação em Saúde).

3. Cecílio L. [Technical health care models: from the pyramid to the circle, a possibility to be explored]. Cad Saúde Pública. 1997; 13(3): 469-78. Portuguese.

4. Poll MA, Lunardi VL, Lunardi Filho WD. [Healthcare in emergency units: organization and ethical implications]. Acta Paul Enferm. 2008; 21(3): 509-14. Portuguese.

5. Benevides R, Passos E. [The humanization of healthcare: a new fad?]Interface Comun Saúde Educ. 2005; 9(17): 389-406. Portuguese.

6. Brasil. Ministério da Saúde. Relatório. Oficina Nacional HumanizaSUS: construindo a política nacional de humanização; 2003 Nov 19-20; Brasilia. Brasília(DF): Ministério da Saúde; 2003.

7. Franco TB, Bueno WS, Merhy EE. ["User embracement" and the working process in health: Betim's case, Minas Gerais, Brazil] G. Cad Saúde Pública. 1999; 15(2):345-53. Portuguese.

8. Brasil. Ministério da Saúde. Política Nacional de Humanização. Brasília: Ministério da Saúde; 2004.

9. Brasil. Ministério da Saúde. Secretaria de Atenção à Saúde. Política nacional de humanização da atenção e gestão do SUS. Humaniza SUS. Acolhimento e classificação de risco nos serviços de urgência.. Brasília: Ministério da Saúde; 2009.
(Série B. Textos Básicos de Saúde).

10. Silva EM, Tronchin DM. [Reception of pediatric emergency room users from the perspective of nurses]. . Acta Paul Enferm. 2011; 24(6):799-803. Portuguese.

11. Barakat SF. Caracterização da demanda do Serviço de Emergências Clínicas de um hospital terciário do Município de São Paulo [tese]. São Paulo: Universidade de São Paulo, Faculdade de Medicina; 2004.

12. Simons DA. Avaliação do perfil da demanda na unidade de emergência em Alagoas a partir da municipalização da saúde e do Programa Saúde da Família [tese]. Recife: Fundação Oswaldo Cruz, Centro de Pesquisas Aggeu Magalhães; 2008.

13. Salla J, Ghellar M, Kaufmann ML, Ilha NS, Frandoloso PR. Perfil de demanda de um serviço de Pronto-Socorro, Santa Maria. Saúde (Santa Maria). 1989; 15(1/2): 71-80.

14. Peixoto Filho AJ, Vasconcelos FA, Silva RM, Botelho LJ. Avaliação da gravidade dos atendimentos no Serviço de Emergência do Hospital Universitário da UFSC. ABM Rev Assoc Med Bras. 1991; 37(2): 91-5.

15. Furtado BM, Araújo Jr. JL, Cavalcanti P. [Profile of emergency users of Hospital da Restauração: an analysis of impacts following the municipalization of healthcare] . Rev Bras Epidemiol. 2004; 7(3):279-89. Portuguese.

16. Azevedo AL, Pereira AP, Lemos C, Coelho MF, Chaves LD. [Organization of hospital emergency services: integrative research review]. Rev Eletrônica Enferm [Internet]. 2010 [citado 2012 Set 10]; 12(4): [about 9p]. Portuguese. Available from: http:/ / www.revistas.ufg.br/index.php/fen/article/ view/6585/8497 